\title{
Concordance between cytopathology and incisional biopsy in the diagnosis of oral squamous cell carcinoma
}

Karla Bianca Fernandes da Costa Fontes $^{(a)}$

Karin Soares Gonçalves Cunha ${ }^{(b)}$ Fabiana Resende Rodrigues ${ }^{(b)}$ Licínio Esmeraldo da Silva ${ }^{(c)}$ Eliane Pedra Dias ${ }^{(b)}$

\footnotetext{
(a) Department of Specific Formation, School of Dentistry, Polo Univ de Nova Friburgo Univ Federal Fluminense - UFF, Nova Friburgo, Rio de Janeiro, Brazil.

(b) Postgraduate Program of Pathology, School of Medicine, Univ Federal Fluminense - UFF, Niterói, Rio de Janeiro, Brazil.

(c)Department of Statistics, Institute of Mathematics, Univ Federal Fluminense UFF, Niterói, Rio de Janeiro, Brazil.
}

Declaration of Interests: The authors certify that they have no commercial or associative interest that represents a conflict of interest in connection with the manuscript.

\section{Corresponding Author:}

Karla Bianca Fernandes da Costa Fontes

E-mail:karlabiancafontes@gmail.com

Submitted: Aug 22, 2012

Accepted for publication: Jan 08, 2013

Last revision: Jan 23, 2013

\begin{abstract}
Oral cytopathology is a simple, non-invasive technique that could be used for early detection of oral premalignant and malignant lesions, but the effectiveness of this diagnostic approach remains controversial. The aim of this study was to evaluate the sensitivity, specificity, positive and negative predictive values, and accuracy of cytopathology for diagnosing oral squamous cell carcinoma (OSCC) and the diagnostic concordance between cytopathological and histopathological diagnoses. The study enrolled 172 patients at outpatient clinics who presented with oral lesions suspicious of malignancy. All patients underwent oral cytological scrapes followed by an incisional biopsy. Of 148 cases that were histopathologically diagnosed with OSCC, the cytopathological method diagnosed 123 positive cases and resulted in a suspicion of OSCC in 16 patients. Based on these data, the sensitivity was $83.1 \%$, the specificity was $100.0 \%$, the positive predictive value was $100.0 \%$, the negative predictive value was $49.0 \%$, and the accuracy was $85.5 \%$. The diagnostic concordance between histopathological and cytopathological examinations was $83.1 \%$ for OSCC and $85.7 \%$ for non-neoplastic lesions. The results indicate that cytopathological diagnosis had good concordance with histopathological diagnosis and showed high sensitivity, specificity, positive predictive value, and accuracy. We conclude that the sensitivity of oral cytopathology is sufficient to justify its use as a diagnostic screening test and to confirm the malignant nature of epithelial cells, mainly for the classification of OSCC. Therefore, cytopathology may be a reliable method for referring patients who require diagnosis of suspected oral cancer for starting treatment.
\end{abstract}

Descriptors: Carcinoma, Squamous Cell; Mouth; Sensitivity and Specificity.

\section{Introduction}

Despite the wide use of cytopathological methods in many specialties of medicine, oral cytopathology is still controversial. ${ }^{1}$ Although many studies have been carried out, different opinions have been reported regarding the effectiveness of cytopathology as a diagnostic method for oral squamous cell carcinoma (OSCC) and oral premalignant lesions. ${ }^{2,3}$

Several studies have demonstrated the effectiveness of cytopathology for the diagnosis of oral premalignant lesions and OSCC, ${ }^{1,3-5}$ and Fontes et al. ${ }^{1}$ stated that oral cytopathology is a reliable diagnostic tool for the 
referral of patients for immediate treatment. Despite good results, however, few physicians and dentists use this method for routine diagnosis of oral cancer. ${ }^{1}$ Moreover, no standardization exists for the cytopathological classification of oral premalignant and malignant lesions, ${ }^{1}$ as exists for the cervix.

To investigate the effectiveness of conventional cytopathology for the diagnosis of OSCC, this study aimed to evaluate its sensitivity, specificity, positive and negative predictive values (PPV and NPV), and accuracy, and the diagnostic concordance between cytopathological and histopathological diagnoses of OSCC in patients with oral lesions clinically suspicious of malignancy.

\section{Methodology}

This study was approved by the research ethics committee of the School of Medicine, Fluminense Federal University (UFF), Niterói, Brazil. The study sample consisted of 172 patients with oral lesions clinically suspicious of malignancy who sought treatment in the outpatient clinic of oral diagnosis at Antônio Pedro University Hospital/UFF, Niterói, Brazil, and from other outpatient clinics enrolled in this study from 2002 to 2010.

Each patient was given a clinical examination. For conventional smears, the oral lesions were scraped with a cytobrush device by applying pressure and rotation. The cells were immediately smeared on a clean frosted glass slide and fixed in $95 \%$ ethanol. Then, an incisional biopsy was performed, and the specimen was fixed in $10 \%$ formalin.

The cytopathological smears were stained with the Papanicolaou method. Biopsy specimens were embedded in paraffin, and $5-\mu \mathrm{m}$ thick sections were obtained from paraffin blocks and stained with hematoxylin-eosin (H\&E) according to the protocol established by the anatomic pathology service of the Antônio Pedro University Hospital/UFF. The smears were evaluated at different times by three independent pathologists, and discordant results were reviewed and discussed until a consensus was reached. The cytopathological criteria were:

- necrosis,

- atypical squamous cells,

- hyperkeratosis,
- hyperchromasia,

- increased nuclear/cytoplasmic ratio,

- anisocytosis,

- multinucleation,

- nuclear molding,

- nuclear pleomorphism,

- karyomegaly,

- anisokaryosis,

- abnormal chromatin pattern,

- irregular nuclear membrane,

- thickened nuclear membrane,

- multiple nucleoli,

- macronucleoli,

- prominent nucleoli, and

- atypical mitotic figures.

Based on these criteria and the absence of cytopathological classification of oral premalignant and malignant lesions, the cytopathological results were grouped by nuclear and cellular features, according to the protocol established by Fontes et al. ${ }^{1}$ as follows:

- positive for squamous cell carcinoma,

- positive for carcinoma,

- positive for malignancy,

- suspicious for squamous cell carcinoma,

- positive for epithelial dysplasia,

- negative for malignancy, and

- inadequate material for cytopathological analysis.

Slides containing histopathological sections were evaluated according to the morphologic criteria established by the World Health Organization. ${ }^{6}$ The results obtained with the cytopathological and histopathological methods were compared to assess the degree of concordance.

\section{Statistical analysis}

Binary proportions were assessed with the binomial test. The concordance between cytopathological and histopathological diagnoses was assessed by the proportions of coincident diagnoses. The diagnostic tests were evaluated by the parameters of sensitivity, specificity, PPV, NPV, and accuracy. These estimates are presented as point estimate $(\%) \pm 95 \%$ 
Table 1 - Comparison of cytopathological and histopathological diagnoses.

\begin{tabular}{|c|c|c|c|c|c|c|c|c|c|}
\hline & \multicolumn{7}{|c|}{ Cytopathological diagnosis } & \multirow{2}{*}{ Total } \\
\hline & & SCC & Carcinoma & Malig & Susp & ED & Neg & IM & \\
\hline \multirow{9}{*}{$\begin{array}{c}\text { Histopathological } \\
\text { diagnosis }\end{array}$} & Squamous cell carcinoma & 123 & 2 & - & 16 & 2 & - & 5 & 148 \\
\hline & Basaloid squamous cell carcinoma & - & 2 & - & - & - & - & - & 2 \\
\hline & Verrucous carcinoma & - & - & - & - & 2 & - & - & 2 \\
\hline & Spindle cell carcinoma & - & 1 & - & - & - & - & - & 1 \\
\hline & Adenosquamous carcinoma & - & 1 & - & - & - & - & - & 1 \\
\hline & Mucoepidermoid carcinoma & - & 1 & - & - & - & - & - & 1 \\
\hline & Basal cell adenocarcinoma & - & 1 & - & - & - & - & - & 1 \\
\hline & Epithelial dysplasia & - & - & - & - & 6 & 1 & 2 & 9 \\
\hline & Non-neoplastic lesion & - & - & - & - & - & 6 & 1 & 7 \\
\hline \multicolumn{2}{|r|}{ Total } & 123 & 8 & - & 16 & 10 & 7 & 8 & 172 \\
\hline
\end{tabular}

SCC = positive for squamous cell carcinoma; Carcinoma = positive for carcinoma; Malig = positive for malignancy; Susp = suspicious for squamous cell carcinoma; $E D$ = positive for epithelial dysplasia; $\mathrm{Neg}=$ negative for malignancy; $\mathrm{IM}$ = inadequate material for cytopathological analysis.

confidence interval. Statistical significance was established at the level of $0.05(5 \%)$.

\section{Results}

The sample included 172 patients (114 men, 58 women) age 20 to 93 years old. The histopathological diagnoses were:

- 148 (86.0\%) squamous cell carcinomas,

- $2(1.2 \%)$ basaloid squamous cell carcinomas,

- $2(1.2 \%)$ verrucous carcinomas,

- $1(0.6 \%)$ spindle cell carcinoma,

- $1(0.6 \%)$ adenosquamous carcinoma,

- $1(0.6 \%)$ mucoepidermoid carcinoma,

- $1(0.6 \%)$ basal cell adenocarcinoma,

- 9 (5.2\%) epithelial dysplasias, and

- 7 (4.0\%) non-neoplastic lesions (NNL).

The cases that were considered NNL were diagnosed as:

- non-specific mucositis $(\mathrm{n}=5)$,

- lichen planus $(\mathrm{n}=1)$, and

- necrotizing sialometaplasia $(\mathrm{n}=1)$.

The cytopathological results were distributed as follows:

- $123(71.5 \%)$ positive for squamous cell carcinoma,

- $8(4.6 \%)$ positive for carcinoma,
- $16(9.3 \%)$ suspicious for squamous cell carcinoma,

- $10(5.8 \%)$ positive for epithelial dysplasia,

- $7(4.1 \%)$ negative for malignancy, and

- 8 (4.6\%) inadequate material for cytopathological analysis (Table 1).

Of the 148 cases histopathologically diagnosed as OSCC, the cytopathological method diagnosed 123 cases and was suspicious in 16 cases. Of the seven NNLs, six were confirmed by cytopathology. Considering only cases in which the cytopathological method confirmed the diagnosis, the diagnostic concordance between histopathological and cytopathological examinations was $83.1 \%$ for OSCC $(95 \%$ confidence level, confidence interval $77.1 \%-89.1 \%$ ) and $85.7 \%$ for NNL $(95 \%$ confidence level, confidence interval $59.8 \%-100.0 \%$ ). In both cases, the proportions were significantly different according to the binomial test $(50 \%-50 \%)(\mathrm{p}=0.005)$.

Considering only the OSCC results, statistical tests for evaluating the quality of cytology as a diagnostic method for OSCC showed no false positive or false negative cases (because no OSCC was cytopathologically diagnosed as negative for malignancy) and 123 true positive cases (Table 1). Based on these data, the sensitivity was $83.1 \%$, the specificity was $100.0 \%$, the PPV was $100.0 \%$, the NPV was $49.0 \%$, and the accuracy was $85.5 \%$ (Table 2 ). 
Table 2 - Estimated values and confidence intervals $(\mathrm{Cl})$ of conventional cytopathology as a method of diagnosis.

\begin{tabular}{|c|c|c|c|c|c|c|}
\hline $\begin{array}{l}\text { Cytopathological } \\
\text { diagnosis }\end{array}$ & Values & Sensitivity & Specificity & $\begin{array}{c}\text { Positive } \\
\text { predictive value }\end{array}$ & $\begin{array}{c}\text { Negative } \\
\text { predictive value }\end{array}$ & Accuracy \\
\hline \multirow{2}{*}{$\begin{array}{l}\text { Positive for squamous } \\
\text { cell carcinoma }\end{array}$} & Point estimates & $83.1 \%$ & $100.0 \%$ & $100.0 \%$ & $49.0 \%$ & $85.5 \%$ \\
\hline & $95 \% \mathrm{Cl}$ & (77.1\%-89.1\%) & (86.2\%-100.0\%) & (97.0\%-100.0\%) & (35.0\%-63.0\%) & (80.2\%-90.7\%) \\
\hline \multirow{2}{*}{$\begin{array}{l}\text { Positive for squamous } \\
\text { cell carcinoma and } \\
\text { positive for carcinoma }\end{array}$} & Point estimates & $84.0 \%$ & $100.0 \%$ & $100.0 \%$ & $39.0 \%$ & $85.5 \%$ \\
\hline & $95 \% \mathrm{Cl}$ & (78.2\%-89.7\%) & (80.6\%-100.0\%) & (97.2\%-100.0\% & $(24.1 \%-54.0 \%)$ & $(80.2 \%-90.7 \%)$ \\
\hline
\end{tabular}

Grouping the cases diagnosed as positive for OSCC and positive for carcinoma, the sensitivity was $84.0 \%$, the specificity was $100.0 \%$, the PPV was $100.0 \%$, the NPV was $39.0 \%$, and the accuracy was $85.5 \%$ (Table 2).

\section{Discussion}

The high mortality rate for oral cancer is due to several factors, but unquestionably we believe that the most important reason is a delay in diagnosis. Oral lesions are easily accessible; therefore, OSCC should be identified early because early diagnosis is also important for effective treatment. However, patients are often diagnosed with advanced-stage disease. In most cases, diagnosis is delayed because the patient does not seek treatment or does not have easy access to professionals to diagnose the disease.

The oral cytopathology method is a simple, noninvasive, relatively painless, and rapid diagnostic technique. ${ }^{2}$ Therefore, it is suitable for routine application in screening programs, early analysis of suspicious lesions, and post-treatment monitoring of malignant lesions. ${ }^{1,3,5}$ The real value of this technique for the early detection of OSCC is controversial. Although many studies have demonstrated the value of oral cytopathology as a diagnostic tool for OSCC, ${ }^{1,3-5,7}$ other professionals disagree with its application..$^{8,9}$

In the present study, cytopathology confirmed the histopathological diagnosis in $83.1 \%$ of OSCC cases, and good diagnostic concordance was observed between histopathological (gold standard) and cytopathological methods. Furthermore, the cytopathological method resulted in at least a suspicion of a malignant lesion in $95.3 \%$ of cases (123 positive for OSCC, 2 positive for carcinoma, and 16 suspicious for OSCC). Considering only those cases with sufficient material for analysis (five cases were excluded because of insufficient material), the diagnostic concordance was $98.6 \%$.

In our previous study, which included $50 \mathrm{pa}$ tients, $74.0 \%$ of all cases showed concordance between histopathological and cytopathological methods for the diagnosis of OSCC. ${ }^{1}$ Using these two methods, Roco Pérez et al. ${ }^{7}$ showed 97.6\% (40/41) coincident diagnoses, and Driemel et al. ${ }^{10}$ identified approximately $80 \%$ of oral malignancies. However, Campagnoli et al. ${ }^{11}$ confirmed the diagnosis in only $44.1 \%$ of 19 patients with oral carcinoma.

In the several studies that analyzed the application of cytopathology as a diagnostic method for oral cancer, ${ }^{2,4,5,7-17}$ the sensitivity ranged between $71.4 \%$ and $100.0 \%$, specificity between $3.0 \%$ and $100.0 \%$, PPV between $10.6 \%$ and $100.0 \%$, NPV between $60.0 \%$ and $100 \%$, and accuracy between $13.2 \%$ and $96 \% .^{7-10,12-17}$ Our results are within the limits reported in the literature, and we observed high sensitivity and accuracy with maximum values of specificity and PPV.

The discrepancy among the values in these studies can be explained by differences in study design. ${ }^{18}$ In our opinion, many factors contribute to the differences in these results:

- non-standardization of the technique,

- different methods of statistical analysis,

- non-representative samples,

- different instruments to collect the sample (brush biopsy, wooden spatula, metal spatula, plastic spatula, toothbrush),

- different methods (conventional cytology, liquidbased cytology, computer-assisted analysis),

- different sample collection sites, 
- differences in the professional who performed the smear,

- inadequate cellularity of the smear and, mainly,

- the experience of the pathologist.

Another important criterion that could affect the results is what is considered a positive case. ${ }^{9}$ Some studies consider "atypical" cases as showing positive results. In our opinion, atypical or dysplastic cases should not be considered positive because, if classified this way, these lesions should be treated the same as malignant lesions. For statistical analysis, we prefer to consider these results as negative cases.

In the present study, false positive or negative cases were not observed. Although the results demonstrated low NPV (49.0\%), no OSCC was diagnosed by the cytopathological method as negative for malignancy. The low NPV can be explained by the fact that it was necessary to group the results into two categories to perform the correct statistical analysis:

- cases in which the cytopathological diagnoses were not conclusive for OSCC (i.e., positive for carcinoma, suspicious for OSCC, epithelial dysplasia, and insufficient material for analysis) and

- cases in which the cytopathological diagnoses were conclusive for OSCC (i.e., positive for OSCC).

The cytopathological method is not intended as a substitute for histopathology because the main goal is not to evaluate the same spectrum of abnormalities as histopathology and because the methods are not mutually exclusive but complementary. ${ }^{11,18,19}$ In fact, the histopathological examination constitutes the gold standard for diagnosing oral cancer and oral premalignant lesions. ${ }^{20}$ We believe, however, that in these lesions the histopathological method should always be performed when the cytopathological diagnosis is not conclusive, i.e., suspicious for OSCC or positive for epithelial dysplasia. When the cytopathological diagnosis is conclusive for OSCC, this result should be used to refer the patient to the oncology center for therapy, reducing the time between diagnosis and treatment.

The limitations of the cytopathological technique include the risk of false-negative results if the collected sample is superficial, ${ }^{12}$ if only keratinized cells from well-differentiated and keratotic lesions are observed in smears, and cases of malignant lesions with little nuclear atypia. ${ }^{3,21}$ In the present study, we recognized these limitations in two cases of welldifferentiated OSCC and two verrucous carcinomas, which presented with a cytopathological result of epithelial dysplasia. Many studies have utilized a specialized stiff brush, which collects a transepithelial sample and avoids superficial samples. . $^{2,9,13,16}$

Another limitation of conventional oral cytology is the small number of cells in the smear. We attempted to understand why cytopathology was not conclusive in some OSCC cases in our results, and we found that the majority of these smears showed low cellularity. Therefore, an adequate sample is essential for a morphological evaluation to yield representative findings. ${ }^{20,22}$ We believe that if the sample is obtained by a professional who performs a highquality oral examination, carefully selects the best site and type of procedure to collect the sample, and if the sample is analyzed by an experienced pathologist, the rate of inadequate sample can be reduced, as in our study, which showed a low rate of inadequate sampling for cytopathological analysis (4.6\%).

\section{Conclusion}

Our results indicate that conventional cytopathology had good diagnostic concordance with the histopathological method and also showed high sensitivity, specificity, PPV, and accuracy. The sensitivity of oral cytopathology is sufficient to justify its widespread use not only as a diagnostic screening test but also to confirm the malignant nature of the epithelial cells, mainly for the classification of lesions that are OSCC. Therefore, cytopathology could also be used as a reliable method for referring patients who require diagnosis of suspected oral cancer for starting treatment.

\section{Acknowledgements}

This study was supported by grants from Coordenação de Aperfeiçoamento de Pessoal de Nível Superior (CAPES), a Brazilian governmental institution. 


\section{References}

1. Fontes KB, Milagres A, Piragibe MMM, Silva LE, Dias EP. Contribution of cytopathology to the diagnosis of oral squamous cells carcinoma. J Bras Patol Med Lab. 2008 Feb $20 ; 44(1): 17-24$.

2. Mehrotra R, Gupta A, Singh M, Ibrahim R. Application of cytology and molecular biology in diagnosing premalignant or malignant oral lesions. Mol Cancer. 2006 Mar 23;5(11):111.

3. Navone R, Pentenero M, Gandolfo S. Liquid-based cytology in oral cavity squamous cell cancer. Curr Opin Otolaryngol Head Neck Surg. 2011 Apr;19(2):77-81.

4. Navone R. Cytology of the oral cavity: a re-evaluation. Pathologica. 2009 Feb;101(1):6-8.

5. Gupta A, Singh M, Ibrahim R, Mehrotra R. Utility of toluidine blue staining and brush biopsy in precancerous and cancerous oral lesions. Acta Cytol. 2007 Sep-Oct;51(5):788-94.

6. Barnes L, Eveson JW, Reichart P, Sidransky D. World Health Organization classification of tumours. Pathology \& genetics head and neck tumours. Lyon: IARC; 2005. Chapter 4, Squamous cell carcinoma; p. 168-75.

7. Roco Pérez OG, Arredondo López M, Alvarez Navarro MC. Citología exfoliativa en el diagnóstico precoz de lesiones oncológicas bucales. Rev Cubana Estomatol. May-Aug. 2002;39(2):89-100.

8. Rick GM, Slater L. Oral brush biopsy: the problem of false positives. Oral Surg Oral Med Oral Pathol Oral Radiol Endod. 2003 Sep;96(3):252.

9. Poate TW, Buchanan JA, Hodgson TA, Speight PM, Barrett AW, Moles DR, et al. An audit of the efficacy of the oral brush biopsy technique in a specialist oral medicine unit. Oral Oncol. 2004 Sep;40(8):829-34.

10. Driemel O, Kunkel M, Hullmann M, Kleinsasser N, Staudenmaier R, Muller-Richter U, et al. [Performance of conventional oral brush biopsies]. HNO. 2008 Feb;56(2):205-10. German.

11. Campagnoli EB, Sandrin R, Braosi APR, Lima AAS, França BHS, Machado MA. Citologia em base líquida - uma nova opção para o diagnóstico de lesões bucais. Rev Bras Patol Oral. 2005;4(2):119-27.
12. Potter TJ, Summerlin DJ, Campbell JH. Oral malignancies associated with negative transepithelial brush biopsy. J Oral Maxillofac Surg. 2003 Jun;61(6):674-7.

13. Remmerbach TW, Hemprich A, Böcking A. [Minimally invasive brush-biopsy: innovative method for early diagnosis of oral squamous cell carcinoma]. Schweiz Monatsschr Zahnmed. 2007;117(9):926-40. German.

14. Driemel O, Dahse R, Berndt A, Pistner H, Hakim SG, Zardi $\mathrm{L}$, et al. High-molecular tenascin- $\mathrm{C}$ as an indicator of atypical cells in oral brush biopsies. Clin Oral Investig. 2007 Mar;11(1):93-9.

15. Driemel O, Dahse R, Hakim SG, Tsioutsias T, Pistner H, Reichert TE, et al. Laminin-5 immunocytochemistry: a new tool for identifying dysplastic cells in oral brush biopsies. Cytopathology. 2007 Dec;18(6):348-55.

16. Mehrotra R, Singh MK, Pandya S, Singh M. The use of an oral brush biopsy without computer-assisted analysis in the evaluation of oral lesions: a study of 94 patients. Oral Surg Oral Med Oral Pathol Oral Radiol Endod. 2008 Aug;106(2):246-53.

17. Rahman F, Tippu SR, Khandelwal S, Girish KL, Manjunath $\mathrm{BC}$, Bhargava A. A study to evaluate the efficacy of toluidine blue and cytology in detecting oral cancer and dysplastic lesions. Quintessence Int. 2012 Jan;43(1):51-9.

18. Eisen D, Frist S. The relevance of the high positive predictive value of the oral brush biopsy. Oral Oncol. 2005 Aug;41(7):753-5.

19. Eisen D, Frist S. Efficacy of the brush biopsy. J Oral Maxillofac Surg. 2003 Oct;61(10):1237.

20. Mehrotra R. The role of cytology in oral lesions: a review of recent improvements. Diagn Cytopathol. 2012 Jan;40(1):7383.

21. Slater LJ. Brush biopsy: false negative results. J Oral Maxillofac Surg. 2004;62(6):764.

22. Mehrotra R, Hullmann M, Smeets R, Reichert TE, Driemel O. Oral cytology revisited. J Oral Pathol Med. 2009 Feb;38(2):161-6. 